\author{
Military Technical College \\ Kobry El-Kobbah, \\ Cairo, Egypt
}

\section{$7^{\text {th }}$ International Conference on Electrical Engineering \\ ICEENG 2010}

\title{
Optimal electric field performance of EHV transmission lines using ground shield conductors
}

\author{
By \\ Mohamed A. Abou El-Ata*
}

\section{$\underline{\text { Abstract: }}$}

Assessment and mitigation of the environmental impact of EHV power lines is a subject of current research due to the possible associated health hazards. The electric field beneath the line and the field on the conductor surface are known to be main sources of concern from an environmental standpoint. The present approach serves as means of reducing the electric field under EHVAC lines using ground shield wires. The aim is to determine the optimal ground shield wire heights and clearances to satisfy a set of field limitations on the conductors as well as on the ground. Genetic Algorithms, GAs, are employed to arrive at the required optimal clearances through an appropriate fitness function. The merits of the proposed approach are demonstrated for 3-phase horizontally-arranged $500 \mathrm{kV}$ single circuit transmission line. Results show the effectiveness and accuracy of the proposed approach.

\section{Keywords:}

ground shield wires, electric field mitigation, transmission lines, genetic algorithms.

* Department of Electrical Engineering, Shoubra Faculty of Engineering, Benha University, Cairo, Egypt 


\section{Introduction:}

Environmental performance of high voltage power lines has been the target of various research studies over the last few decades [1-6]. Field effects and corona-generated audible and radio noise are among the most important aspects that have to be addressed when assessing the line impact on its neighboring environment. Recent biological studies on electric and magnetic field effects have largely enhanced concern of possible health hazards to nearby living species [1-6]. Trends towards higher transmission voltages, with possibly increased field and interference levels, are contributing to such concerns.

Several techniques may be applied to reduce electric and magnetic fields such as reverse phase, split phase, shielding with loops or materials and underground cabling $[2,3,7,8]$. In general, shielding of the electric field can be achieved by simply introducing conductive material into the field [1,2]. It should be noted that cost and electrical performance of the line strongly dictate the technique to be applied for field reduction. For example, depending on the desired field level, line compaction (bringing the conductors of the power line closer to each other) may be applied. However, this technique is limited as compaction, in turn, affects other electrical parameters, important to the safe and effective operation of the line [2].

Although magnetic field reduction, to a certain extent, can be achieved by line compaction, special designs are required to reduce magnetic fields significantly $[7,8]$. An important technique which, generally, results in exceptional electric field reduction( may reach 10 times) while being low in cost (less than $10 \%$ of the line cost) is to use a wire mesh bonded to earth, called ground shield wires, and supported by wooden poles covering the area that needs to be shielded [1,2]. This approach is suitable as small areas can be shielded at relatively low cost and is feasible for local applications in spite of its possible visual impact [2]. This technique may be very effective for electric field reduction which is further investigated in the present work.

Electric field, $\mathrm{E}_{\mathrm{g}}$, beneath the line, usually $1 \mathrm{~m}$ above the ground, is influenced by the line voltage, the phase-to-phase spacing $\mathrm{s}$, the line height $\mathrm{h}$ beside the ground shield wires height $\mathrm{Hg}$, and their spacing $\mathrm{S}_{\mathrm{g}}$. Audible noise, tv and radio interference are byproducts of the conductors corona discharges; that occur when the electric field at the conductor surface $E_{c}$ exceeds a certain critical value. In addition to the voltage $V, E_{c}$ is also dependent on the above dimensions. In summary, the electrical field environment of the line may be characterized by the presence of the both fields with the ground 
shield wires height $\mathrm{H}_{\mathrm{g}}$, and their spacing $\mathrm{S}_{\mathrm{g}}$ as well as other related dimensions influencing their values and distributions. Determination of such dimensions is usually subject to various electrical, mechanical, economical, as well as environmental design considerations [3]. Extensive computational and studies over a relatively long period of time are necessary to meet the various requirements of the line design [3].

In this paper, a new approach to the determination of the ground shield wires height $\mathrm{Hg}$, and their spacing $S_{g}$ on primarily environmental basis is proposed. The maximum, $E_{\mathrm{gm}}$, of the electric field distribution at ground as well as the maximum, $\mathrm{E}_{\mathrm{cm}}$, of the electric field at the conductor surface are targeted as a set of parameters that is indicative of the line impact on its environment. The aim is to determine these clearances $H_{g}$ and $S_{g}$ as well as related dimensions such that a prerequisite set of $\mathrm{E}_{\mathrm{cm}}$ and $\mathrm{E}_{\mathrm{gm}}$ appears in the line environment This should provide a considerable saving in the efforts for proper selection of these dimensions and/or the comparative studies of alternate line designs from an environmental standpoint. It is assumed that all variables other than the design of the dimensions $\mathrm{H}_{\mathrm{g}}$ and $\mathrm{S}_{\mathrm{g}}$ have been determined by other considerations.

Genetic algorithms computational schemes are employed in the present work to determine, directly and accurately, the $\mathrm{H}_{\mathrm{g}}$ and $\mathrm{S}_{\mathrm{g}}$ values as well as other related dimensions through the optimization of a relevant fitness function. A genetic model is developed for this purpose. The results of the simulation demonstrate the effectiveness and accuracy of the proposed approach.

\section{Field profiles of EHV lines:}

Overhead transmission lines generate an electrostatic field that introduces design considerations in order to avoid excessive charging currents, induced voltages, or other undesirable effects, and to evaluate possible interactions between such effects and the environment. These effects are mainly dependent on the prevailing electric field beneath the line [3]. The peak electric field is usually taken as a design quantity for each of the possible effects.

The case considered consists of a 3-phase horizontally-arranged $500 \mathrm{kV}$ single circuit transmission line shown in Fig. 1. The phase conductor consists of $2 \times 30 \mathrm{~mm}$ diameter subconductors and $47 \mathrm{~cm}$ subconductor spacing. The phase angle of the middle conductor voltage is taken as the reference. The number of ground shield wires under each phase, $\mathrm{N}_{\mathrm{g}}$, is 3 each of diameter $15 \mathrm{~mm} . \mathrm{S}_{\mathrm{g}}$ is the spacing between the ground shield wires and $\mathrm{H}_{\mathrm{g}}$ is the height. 


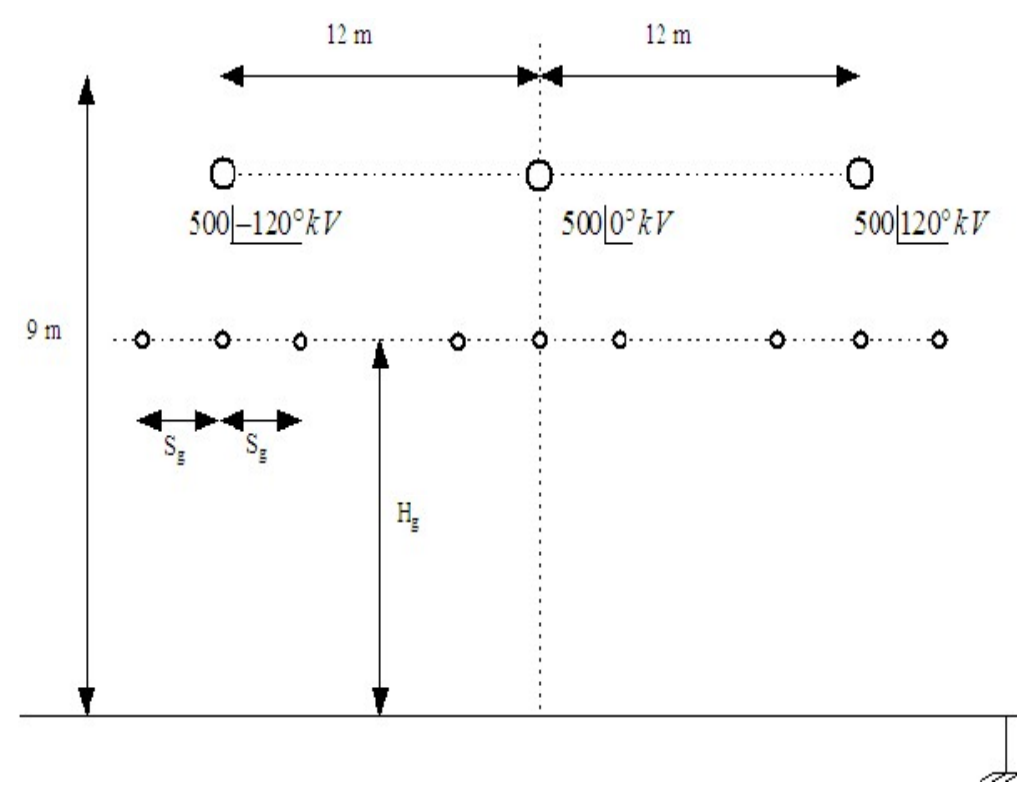

Figure (1): A 500kV single circuit horizontal HVAC transmission line model with 3 ground shield wires

Fig. 2 shows the lateral field distributions for a 3-phase, horizontally-arranged, 500kV single circuit transmission line with and without ground shield wires. The lateral distance $\mathrm{x}$ is measured from the line middle phase. The ground field distribution is symmetric around the center of the middle phase.

The maximum electric field at ground, $\mathrm{E}_{\mathrm{gm}}$, without ground shield wires is $10.18 \mathrm{kV} / \mathrm{m}$ while the maximum electric field at the conductor surface $\mathrm{E}_{\mathrm{cm}}$ is $21.23 \mathrm{kV} / \mathrm{cm}$.

The figure shows the effect of using the ground shield wires at different heights $\mathrm{H}_{\mathrm{g}}$ for $\mathrm{S}_{\mathrm{g}}=0.5 \mathrm{~m}$ upon the electric field distribution on the ground. It is clear that the whole electric field ground profile underneath the line is significantly reduced when ground shield wires are used. $\mathrm{E}_{\mathrm{gm}}$ decreases with increasing $\mathrm{H}_{\mathrm{g}}$; e.g. $\mathrm{E}_{\mathrm{gm}}$ reduced by $45 \%$ for $\mathrm{H}_{\mathrm{g}}$ $=6 \mathrm{~m}$ compared with no shield wires which shows the effectiveness of using the ground shield wires. It can be observed that distributions overlap as $\mathrm{H}_{\mathrm{g}}$ changes and the distribution peak also changes both in value and location. $\mathrm{E}_{\mathrm{gm}}$ decreases by $35 \%$ to $45 \%$ for $\mathrm{H}_{\mathrm{g}}$ varying from $4 \mathrm{~m}$ to $6 \mathrm{~m}$.

Some regularity staffs recommend a $1.6 \mathrm{kV} / \mathrm{m}$ as a maximum allowable electric filed at the edge of the right of way, ROW [4]. With this arrangement, it is found that the ROW is reduced by about $15 \%$ (for $\mathrm{H}_{\mathrm{g}}$ equals $6 \mathrm{~m}$ ) from $34 \mathrm{~m}$ to $29 \mathrm{~m}$. 


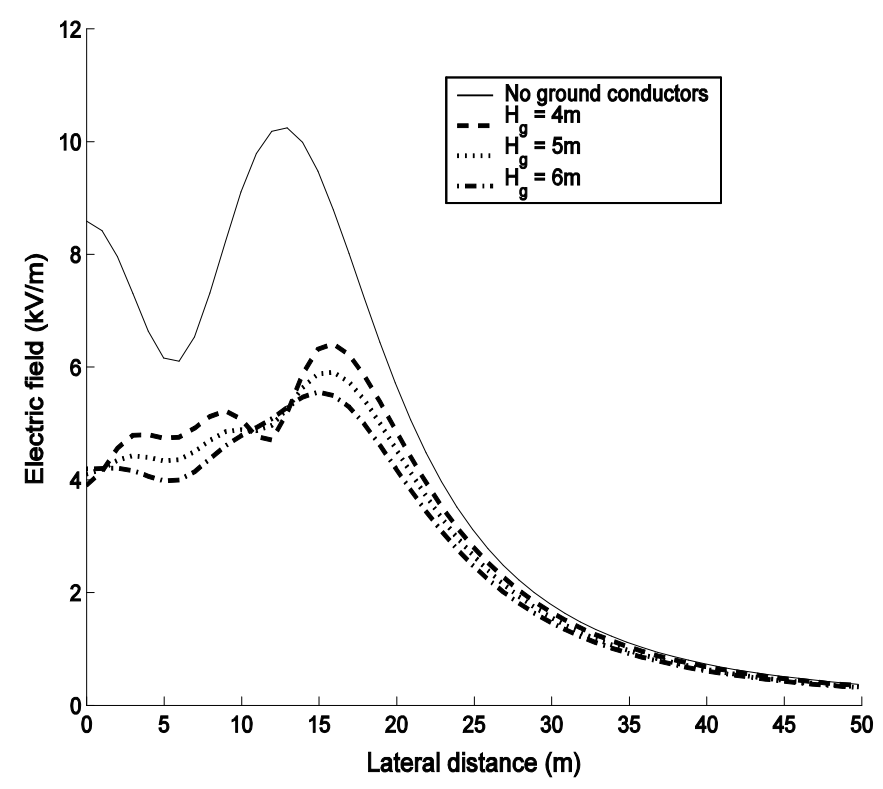

Figure (2): Lateral electric field profiles with\& without ground shield wires ( $N_{g}=3$, and $S_{g}=0.5 \mathrm{~m}$ )

The influence of the ground conductors spacing $S_{\mathrm{g}}$ on the electric field distributions on the ground is shown in Fig. 3. The Fig. shows that $E_{\mathrm{gm}}$ decreases with increasing $\mathrm{S}_{\mathrm{g}}$. It can be seen that the distributions do not overlap and the peak value is less influenced than when $\mathrm{H}_{\mathrm{g}}$ is changed. Variation of $\mathrm{S}_{\mathrm{g}}$ from $0.5 \mathrm{~m}$ to $1 \mathrm{~m}$ results in reduction of $\mathrm{E}_{\mathrm{gm}}$ and ROW by $7 \%$.and $9 \%$ respectively.

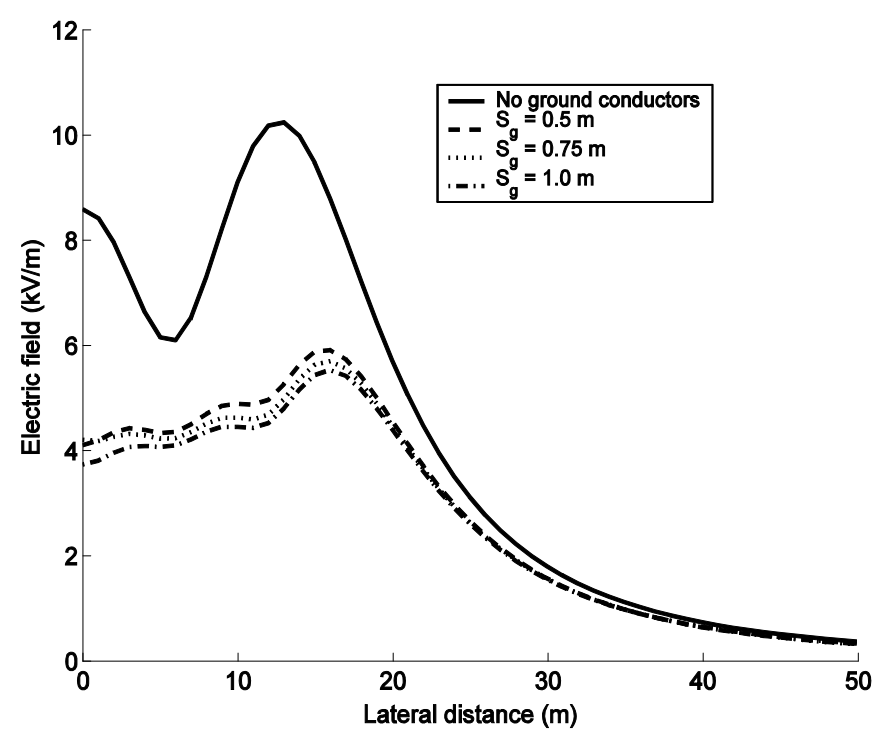

Figure (3): Lateral electric field profiles with\& without ground shield wires ( $N_{g}=3$, and $H_{g}=5 \mathrm{~m}$ ) 
The variation of the maximum electric field at ground $\mathrm{E}_{\mathrm{gm}}$ with $\mathrm{S}_{\mathrm{g}}$ for different $\mathrm{H}_{\mathrm{g}}$ is shown in Fig.4. $\mathrm{E}_{\mathrm{gm}}$ decreases as $\mathrm{S}_{\mathrm{g}}$ increases for the range of $\mathrm{H}_{\mathrm{g}}$ considered with about $10 \%$. For a certain $\mathrm{S}_{\mathrm{g}}$, the effect of varying $\mathrm{H}_{\mathrm{g}}$ becomes less significant as $\mathrm{H}_{\mathrm{g}}$ decreases.

Corona effects are usually taken into account when deciding on the dimensions $\mathrm{H}_{\mathrm{g}}$ and $\mathrm{S}_{\mathrm{g}}$. Generation of corona of a bundle conductor is practically determined by the maximum electric field at the surface of the subconductors [3].

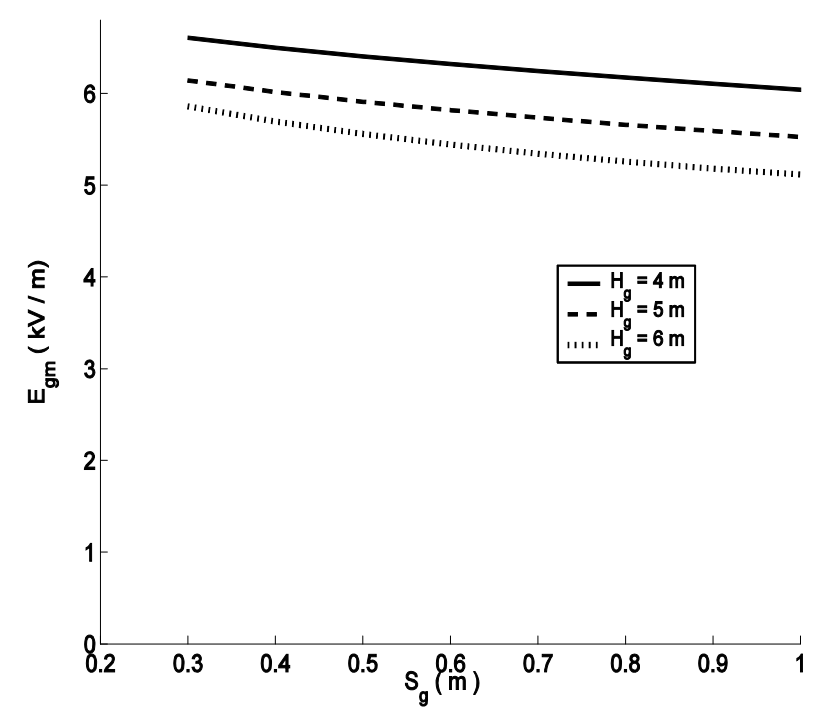

Figure (4): Variation of $E_{g m}$ with $S_{g}$ for different $H_{g}$

The present analysis assumes a single equivalent smooth conductor per phase and that only the maximum conductor electric field is used as reference for the determination of the corona performance of the line conductors. Computations of the electric field showed that the maximum value of the electric field at the conductor surface, $\mathrm{E}_{\mathrm{cm}}$, always occur on the middle phase, while the maximum value of the electric field at the ground shield wires, $\mathrm{E}_{\mathrm{gcm}}$, always occur on the outer shield wire on both sides for a wide range of values of $\mathrm{H}_{\mathrm{g}}$ and $\mathrm{S}_{\mathrm{g}}$.

Fig. 5 shows the variation of $\mathrm{E}_{\mathrm{cm}}$ and $\mathrm{E}_{\mathrm{gcm}}$ with $\mathrm{S}_{\mathrm{g}}$ for different $\mathrm{H}_{\mathrm{g}}$. After using the ground shield wires, $\mathrm{E}_{\mathrm{cm}}$ increased by $7 \%$ at certain $\mathrm{S}_{\mathrm{g}}$ and $\mathrm{H}_{\mathrm{g}}$ equals $6 \mathrm{~m}$ compared with no shield wires It can be seen that $E_{c m}$ decreases as $S_{g}$ increases for the range of $\mathrm{H}_{\mathrm{g}}$ considered with about $1 \%$. The influence of $\mathrm{S}_{\mathrm{g}}$ becomes more significant for larger values of $\mathrm{H}_{\mathrm{g}}$. In general, for a certain $\mathrm{H}_{\mathrm{g}}$, it was observed that $\mathrm{E}_{\mathrm{cm}}$ is less affected by the variation of $S_{\mathrm{g}}$ than $\mathrm{E}_{\mathrm{gm}}$. Also, Fig. 5 shows that $\mathrm{E}_{\mathrm{gcm}}$ increases as $S_{\mathrm{g}}$ increases for the range of $\mathrm{H}_{\mathrm{g}}$ considered by $16 \%$. The influence of $\mathrm{S}_{\mathrm{g}}$ becomes more significant for larger values of $\mathrm{H}_{\mathrm{g}}$. 


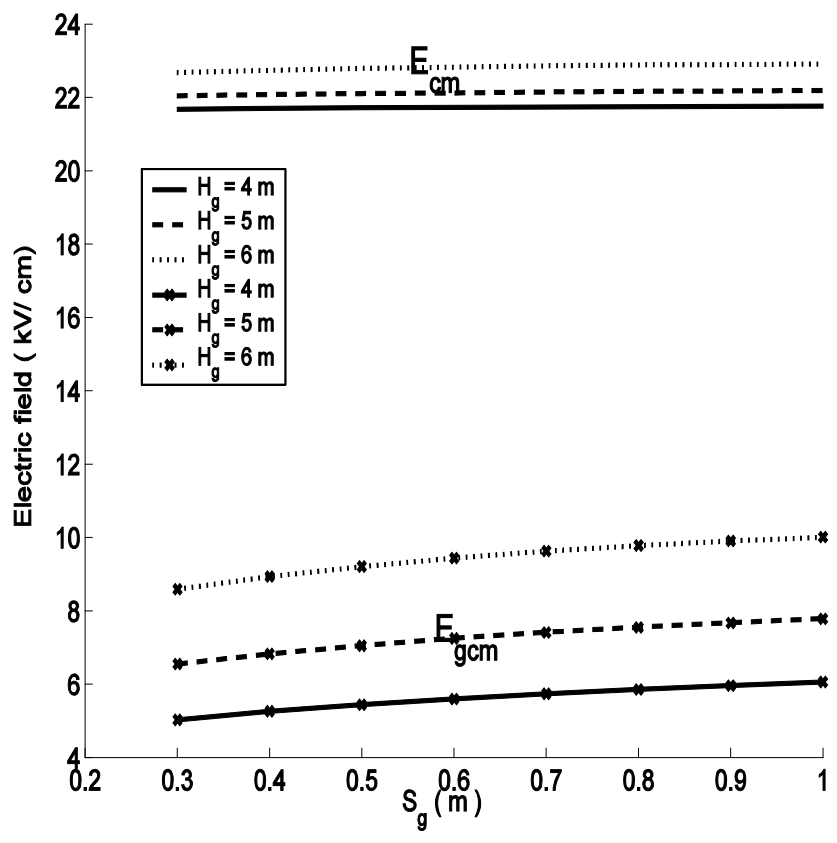

Figure (5): Variation of $E_{c m}$ and $E_{g c m}$ with ground conductors spacing for different $H_{g}$

The variation of the maximum electric field at ground $\mathrm{E}_{\mathrm{gm}}$ with $\mathrm{H}_{\mathrm{g}}$ for different $\mathrm{S}_{\mathrm{g}}$ is shown in Fig.6. $E_{g m}$ decreases as $H_{g}$ increases for the range of $S_{g}$ considered with about $25 \%$. For a certain $H_{g}$, the effect of varying $S_{g}$ becomes less significant as $S_{g}$ increases.

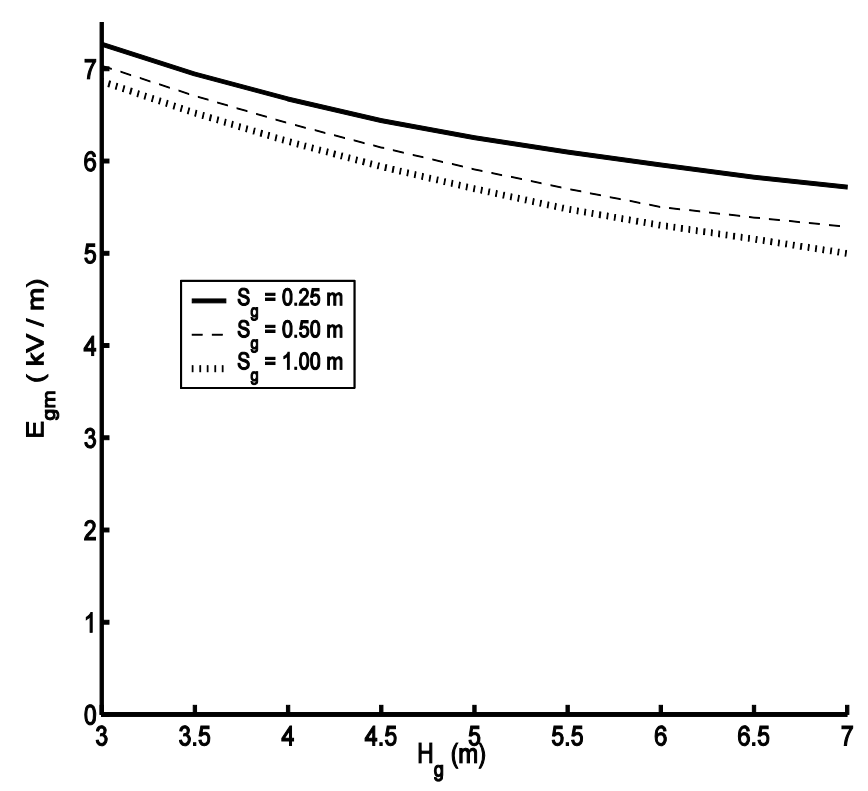

Figure (6): Variation of $E_{g m}$ with ground conductors height for different $S_{g}$ 
Fig. 7 shows the variation of $\mathrm{E}_{\mathrm{cm}}$ and $\mathrm{E}_{\mathrm{gcm}}$ with $\mathrm{H}_{\mathrm{g}}$ for different $\mathrm{S}_{\mathrm{g}}$. It can be seen that $\mathrm{E}_{\mathrm{cm}}$ increases as $\mathrm{H}_{\mathrm{g}}$ increases for the range of $\mathrm{S}_{\mathrm{g}}$ considered by about $11 \%$. The influence of $\mathrm{H}_{\mathrm{g}}$ becomes more significant for larger values of $\mathrm{S}_{\mathrm{g}}$. In general, for a certain $S_{g}$, it was observed that $E_{c m}$ is less affected by the variation of $H_{g}$ than $E_{g m}$. Also, Fig. 7 shows that $\mathrm{E}_{\mathrm{gcm}}$ increases as $\mathrm{H}_{\mathrm{g}}$ increases for the range of $\mathrm{H}_{\mathrm{g}}$ considered. The influence of $\mathrm{H}_{\mathrm{g}}$ becomes more significant for larger values of $\mathrm{S}_{\mathrm{g}}$.

This discussion demonstrates that; from an environmental standpoint, the field values $\mathrm{E}_{\mathrm{cm}}$ and $\mathrm{E}_{\mathrm{gm}}$ can be considered as single set of indicators of the environmental impact of a power line with the ground shield wires dimensions $H_{g}$ and $S_{g}$ controlling their variations, while the field values $\mathrm{E}_{\mathrm{gcm}}$ does not present a problem of the design as their values are lower than the corona field values.

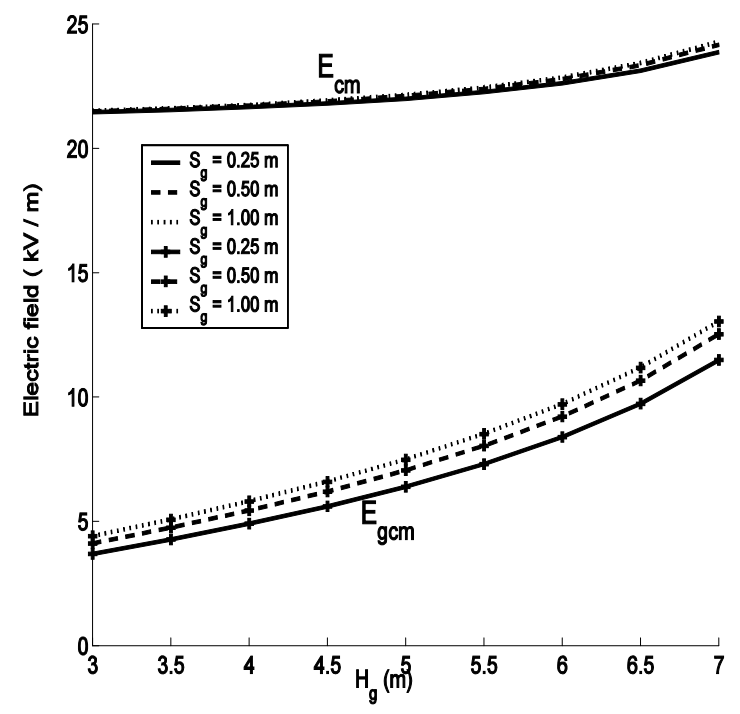

Figure (7): Variation of $E_{c m}$ and $E_{g c m}$ with ground conductors height for different $S_{g}$

\section{Genetic Algorithms:}

Genetic algorithms are search and optimization techniques based on the theory of natural selection $[9,10,11]$. An initial population of a constant size is created from a random selection of the parameters in the parameter space. Each parameter set represents the individual's chromosome. Each of the individuals is assigned a fitness value based on how well each individual chromosome allows it to perform in its environment.

Three basic operations occur in GAs to create the next generation: Selection, Crossover 
and Mutation. More fit individuals are selected for mating while less fit ones diminish. Parents create a child, through the crossover operation, with a chromosome set that is some mix of the parents' chromosomes. Then there is a small probability that one or more of the child's chromosomes will be mutated; thus introducing new individual into the population. The process of mating and child creation is continued until an entirely new population of the same size is generated.

Improvement in the selection scheme can be achieved by introducing elitism into the selection process. The elitist strategy copies the best member of each generation into the succeeding generation. This strategy may increase the speed of domination of a population by a super individual and thus improve the search at the expense of a global perspective, but on balance it tends to improve the GA performance $[9,10,11]$. The above genetic operators are implemented in the present analysis.

\section{Transmission Line Modelling:}

In order to demonstrate the merits of the proposed approach, the above 3-phase horizontally-arranged $500 \mathrm{kV}$ single circuit transmission line is modeled. The dimensions to be optimized are the ground shield wires height $\mathrm{H}_{\mathrm{g}}$, and their spacing $\mathrm{S}_{\mathrm{g}}$. Each parameter is coded as a 15-bit binary string; thus the chromosome length is 30 bits. The error is expressed as follows:

$$
\text { Error }=0.5 *\left[\operatorname{abs}\left(\mathrm{E}_{\mathrm{cmo}}-\mathrm{E}_{\mathrm{cm}}\right)+\mathrm{abs}\left(\mathrm{E}_{\mathrm{gmo}}-\mathrm{E}_{\mathrm{gm}}\right)\right]
$$

where $\mathrm{E}_{\mathrm{cmo}}$ and $\mathrm{E}_{\mathrm{gmo}}$ are the prespecified maximum conductor surface field and the peak electric field at ground respectively. The fitness function to be maximized is given by:

$$
\text { Func }=\max \left[\frac{1}{1+\text { error }}\right]
$$

The number of generations used in the simulation is 2000 and the population size is 5 . The crossover probability is 0.5 and the mutation rate is 0.02 . A practical search space for $S_{\mathrm{g}}$ is taken to lie between $0.4 \mathrm{~m}$ and $0.8 \mathrm{~m} \mathrm{~cm}$ while that for $\mathrm{H}_{\mathrm{g}}$ is between 4 and $6 \mathrm{~m}$.

Table 1 summarizes the simulation results in this case. A practical range for both $\mathrm{E}_{\text {gmo }}$ and $\mathrm{E}_{\mathrm{cmo}}$ is selected for the simulation [3-5]. However, it should be noted that any other value for either $\mathrm{E}_{\mathrm{gmo}}$ or $\mathrm{E}_{\mathrm{cmo}}$ could be used as well as all conductors are assumed to be smooth with surface roughness factor of one. When calculating $E_{g m}$ and $E_{c m}$ using the optimal $\mathrm{H}_{\mathrm{g}}$ and $\mathrm{S}_{\mathrm{g}}$ values, the accuracy of them is found acceptable. It can be seen that 
as $E_{c m o}$ increases, for a given $E_{g m o}$, both $H_{g}$ and $S_{g}$ increases. However, the change in $S_{g}$ is much more pronounced than that of $\mathrm{H}_{\mathrm{g}}$. Also, as $\mathrm{E}_{\mathrm{gmo}}$ varies, for a given $\mathrm{E}_{\mathrm{cmo}}, \mathrm{S}_{\mathrm{g}}$ varies more significantly than $\mathrm{H}_{\mathrm{g}}$. The results demonstrate the effectiveness of the present approach.

Table (1): Results of the simulation

\begin{tabular}{|c|c|c|c|}
\hline $\mathbf{E}_{\mathbf{g m o}}(\mathbf{k V / m})$ & $\mathbf{E}_{\mathbf{c m o}}(\mathbf{k V / c m})$ & $\mathbf{H}_{\mathbf{g}}(\mathbf{m})$ & $\mathbf{S}_{\mathbf{g}}(\mathbf{m})$ \\
\hline \multirow{2}{*}{5} & 21 & 4.81 & 0.64 \\
\cline { 2 - 4 } & 22 & 4.83 & 0.71 \\
\hline \multirow{2}{*}{6} & 21 & 4.32 & 0.52 \\
\cline { 2 - 4 } & 22 & 4.36 & 0.58 \\
\hline \multirow{2}{*}{7} & 21 & 4.01 & 0.41 \\
\cline { 2 - 4 } & 22 & 4.05 & 0.45 \\
\hline
\end{tabular}

\section{Conclusions:}

A new approach to mitigate electric field under EHV power lines using ground shield wires has been presented. The maximum electric field at the ground level $\mathrm{E}_{\mathrm{gm}}$ and the ROW width was reduced using the proposed technique. The influence of increasing the shield wires height $\mathrm{H}_{\mathrm{g}}$ on the reduction of $\mathrm{E}_{\mathrm{gm}}$ was found to be more effective than increasing the shield wires spacing $S_{\mathrm{g}}$. On the other hand, the influence of decreasing the shield wires height $\mathrm{H}_{\mathrm{g}}$ on the reduction of $\mathrm{E}_{\mathrm{cm}}$ and $\mathrm{E}_{\mathrm{gcm}}$ was less effective than decreasing the shield wires spacing $\mathrm{S}_{\mathrm{g}}$. The proposed genetic algorithm scheme offer flexibility, efficiency as well as accuracy for the determination of the optimal ground shield wires height and spacing as well as other related dimensions so that a prespecified set of field values will not be exceeded in the line environment. A 3-phase horizontally-arranged $500 \mathrm{kV}$ single circuit transmission was studied. The results of the simulation demonstrated the effectiveness and accuracy of the proposed approach.

\section{References:}

[1] M.M. Samy, A.M. El-Zein, M.Abdel-Salam," Electric Field Profiles and Right-ofWay Widths as Influenced by Grounded Shield Wires Underneath EHV Direct Current Transmission lines", 12th International Middle-East Power Systems Conf (MEPCON'2008), Aswan, Egypt, march 12 -15, 2008.

[2] P.H.Pretoriu," Electric And Magnetic Fields From Overhead Power Line", A Summary of Technical and Biological Aspects Final Report, Prepared for ESKOM HOLDINGS LTD, 18 August 2006. 
[3] Eskom power series, "The Planning, Design and Construction of Overhead Power Lines", 132kV and Above, Vol. 1, Chapter 15, Feb 2005.

[4] M.Abouelsaad, "Environment-Based Transmission Lines Clearances Using Genetic Algorithms", 7th International Middle-East Power Systems Conf (MEPCON'2000), Ain Shams University, Egypt, march 28 -30, 2000.

[5] R. Conti, et al., "ENEL's Experience in Assessing Occupational and Residential Exposure to Power Frequency Electric and Magnetic Fields", CIGRE, pp.36-104, 1996.

[6] International Commission on nonionizing radiation, " Guidelines for Limiting Exposure to Time-Varying Electric, Magnetic, and Electromagnetic Fields", Health Physics, April 1998, vol. 74, Number 4.

[7] V.S.Rashkes, R.Lordan, "Magnetic Field Reduction Methods: Efficiency and Cost", IEEE Trans on Power Delivery, vol 13, No 2, pp. 552-559, April 1998.

[8] P.Cruz, C.Izquierdo, M.Burgos, "Magnetic Field Mitigation in Power Lines with Passive and Active Loops", CIGRE Session, pp. 36-106, 2002.

[9] D.Goldberg, "Genetic Algorithms in Search, Optimization, and machine Learning", Addison-Wesley, 1989.

[10] S.N.Sivanandam, S.N.Deepa, "Introduction to genetic algorithms", SpringerVerlag Berlin Heidelberg (2008).

[11] R. L. Haupt, D. H. Werner "Genetic Algorithms in Electromagnetics" John Wiley \& Sons, Inc., Hoboken, New Jersey. 2007.

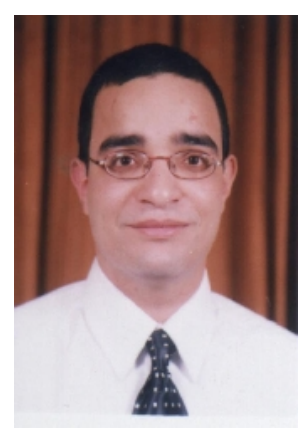

Mohamed A. Abou El-Ata: Obtained his B.sc, M.sc, and Ph.D degrees from Shoubra Faculty of Engineering, Benha University at 2001, 2005, and 2008 respectively. His area of interest is study of electric and magnetic fields under transmission lines and at right of way, electrostatic field effects of EHV lines on objects and partial discharge measurements. His current position now is Assistant Professor, Electrical Power and Machine Department, Shoubra Faculty of Engineering, Benha University. 